\title{
Improving official statistics on stateless people: Challenges, solutions, and the road ahead $^{1}$
}

\author{
Mary Strode ${ }^{\mathrm{a}, *}$ and Melanie Khanna ${ }^{\mathrm{b}}$ \\ ${ }^{a} U N H C R$ EGRIS \\ ${ }^{\mathrm{b}}$ The Statelessness Section, UNHCR
}

\begin{abstract}
Statelessness is the situation of people who are not considered as nationals of any State. The disadvantages of not having a nationality can be severe, as stateless people typically lack access to the socio-economic and political rights enjoyed by citizens. As a result, people without citizenship are particularly vulnerable to severe forms of exploitation and abuse, such as human trafficking. One of the biggest challenges facing advocates is the lack of reliable statistics about statelessness. There is no definitive or reliable global estimate, national figures are scant in most regions of the world, and where they exist, they are often of questionable quality. Furthermore, there are many challenges to collecting data about this marginalised and hidden group who may not wish to declare their status, or may not know of their status in settings where most people lack formal documentation. In order to help address this data gap, a number of actors under the umbrella of the Expert Group on Refugee and IDP Statistics (EGRIS) are now collaborating to produce draft International Recommendations on Statelessness Statistics (IROSS). This paper summarises the progress made to date by the EGRIS in preparing this new set of recommendations for consideration by the UN Statistical Commission.
\end{abstract}

Keywords: EGRIS, IROSS, \#IBelong campaign, people with undetermined nationality, legal identity, statelessness statistics, official statistics

\section{Introduction to the concept of statelessness}

Statelessness, the situation of people who are not considered citizens by any State, is an anomalous social ill that has received greater attention in recent years thanks in part to a global campaign led by the UN Refugee Agency, UNHCR. The \#IBelong Campaign to End Statelessness by 2024 (hereinafter, the \#IBelong Campaign) has helped bring to light the challenges faced by individual stateless people using social media, advocacy events, special reports [1], and international

\footnotetext{
${ }^{1}$ Disclaimer: This article reflects the views of its authors and does not necessarily represent those of the Expert Group on Refugee and IDP Statistics (EGRIS), its member organizations, UNHCR, or the United Nations.

*Corresponding author: Mary Strode, UNHCR EGRIS, E-mail: strode@unhcr.org.
}

conferences. These challenges can include the inability to enjoy basic rights that most people take for granted, including the right to go to school, to see a doctor, to work, to travel, to vote, and even to legally marry. Civil society networks devoted to the issue have sprung up, and governments have taken notice. As of September 2021, there have been twenty-nine new accessions to the UN Statelessness Conventions since the \#IBelong Campaign was launched in 2014. Those treaties contain the international standards that protect stateless people and help to prevent and reduce statelessness itself. In addition, around 800,000 formerly stateless persons have acquired a nationality in the last decade, and Kyrgyzstan has become the first State to declare a resolution of all known cases of statelessness on its territory. Nine States (Albania, Armenia, Chile, Cuba, Estonia, Iceland, Latvia, Luxembourg, Tajikistan) have amended their nationality laws to incorporate provisions to grant 
nationality to children born in their territory who would otherwise be stateless; and at least sixteen States have adopted new Statelessness Determination Procedures (SDPs) so that stateless persons may seek recognition and protection as such. At a 2019 high-level event on statelessness convened by UNHCR, some 360 pledges to take action to tackle statelessness were delivered by States and other actors [2].

These are welcome developments, as the disadvantages associated with not having a nationality are generally experienced by individuals as severe and include heightened vulnerability to the worst forms of exploitation and abuse, including sexual exploitation and human trafficking. As noted above, stateless people typically lack access to the basic socio-economic rights enjoyed by citizens (e.g., education, healthcare, the right to work, the right to own property) as well as to civil and political rights such as the right to vote and participate in the political process through other means. As a result, they often live on the margins of society and find themselves caught up in inter-generational cycles of poverty and vulnerability. When statelessness affects whole ethnic or religious communities within a given society, it can contribute to instability, conflict, and displacement. Addressing it is therefore an imperative that fits squarely within the international community's resolve, as reflected in the Sustainable Development Agenda [3], to "leave no one behind".

On a positive note, statelessness is fully preventable and resolvable through changes in law and policy, and thus the ambition to end it is in principle achievable. Statelessness is caused largely by nationality laws that are inconsistent with international standards [4]. Such laws may discriminate against certain racial, ethnic, or religious groups, for example, in the ability to acquire or confer nationality. They may also limit a woman's ability to confer her nationality upon her children [5]. Or they may provide for loss or deprivation of nationality without safeguards against statelessness. State succession can also be a cause of statelessness if an individual's previous State of nationality ceases to exist, or if the territory on which they live comes under the control of another State and they are not entitled to citizenship under the new citizenship law. Weak birth registration systems can put people at risk of statelessness since a birth certificate contains key information to assert entitlement to nationality, such as place of birth and parentage. As these problems are the main drivers of statelessness globally, laws that conform to international standards and that are implemented without discrimination can go a long way towards preventing statelessness from occurring in the first place. Also important are strong civil registration laws and systems that provide birth registration and certification to all children born on the territory irrespective of the legal status of his or her parents, and at the initiative of either parent [6].

While current efforts to address statelessness are more fruitful in many respects than they have been in recent decades, there is still a long way to go towards the ambitious objective of eradicating statelessness. One of the biggest challenges that advocates face is the lack of reliable statistics on stateless people. Most strikingly, while there are various estimates concerning the number of such persons globally, there is no definitive figure or particularly reliable estimate. Likewise (and relatedly), statistics at the national level are scant in most regions of the world, and the figures that do exist are often of poor quality. This is because most governments simply do not collect any data on statelessness within their borders, either because they do not consider it necessary or important to do so or because they lack reliable methodologies and the required capacity.

The lack of convincing data can make it difficult to motivate national authorities to take the policy measures needed to tackle statelessness, such as facilitating naturalization for stateless people and making reforms to nationality laws to help prevent statelessness from occurring in the first place; it also hampers the ability of agencies like UNHCR to forge stronger global partnerships, including with development actors, who need convincing evidence that statelessness is a significant issue both in terms of its numerical scope and its development (including poverty and access to services) implications. Improving the state of knowledge about statelessness has therefore long been an important goal, as reflected in UNHCR's Global Action Plan to End Statelessness [7].

One fundamental stumbling block when it comes to promoting data collection is the weak understanding among laypeople and government authorities alike as to what statelessness actually is. Article 1 of the 1954 Convention Relating to the Status of Stateless Persons provides the international legal definition of a "stateless person" as "A person who is not considered as a national by any State under the operation of its law" (in other words, a person without any citizenship). Although this definition clearly differentiates statelessness from the situation of most refugees and migrants, statelessness is often confused with refugee status or with the condition of undocumented migrants [8], and national authorities have sometimes employed diverse 
and creative definitions to their own data collection efforts. There is a clear need for international guidance on data collection on statelessness that would address this definitional issue. Currently there are no international recommendations on statelessness statistics endorsed by the UN Statistical Commission that would fill this guidance gap, although such recommendations exist on the two other main population groups that UNHCR works with, namely refugees and internally displaced persons (IDPs) [9]. In order to remedy this, a number of actors under the umbrella of the Expert Group on Refugee and IDP Statistics (EGRIS) are now collaborating to produce draft International Recommendations on Statelessness Statistics (IROSS). The aim is to have the IROSS considered and adopted by the UN Statistical Commission in 2023. This article puts that effort in context by explaining the state of estimates on statelessness currently; setting out core elements of the proposed way forward as they are currently envisaged to be reflected in the IROSS; identifying some of the statistical challenges to improved data collection and some information about attempts to address these to date; and mapping out the road ahead towards potential adoption of the IROSS in 2023.

\section{Data gaps - the availability of estimates of statelessness globally}

UNHCR's annual statistical reporting on statelessness, typically derives from a combination of administrative registers maintained by national statistics offices and line ministries; nationality determination and other registration procedures; census data; household surveys; UNHCR initiatives; civil society and NGO data; and other internal estimates. UNHCR'S own administrative records provide data about 'persons of concern' which include displaced people who are also stateless.

A 2019 UNHCR study on UNHCR Statistical Reporting on Statelessness [10] found the main government sources of statelessness data to be: administrative registers (34), national censuses (9), government estimates (5), household surveys (2), statelessness determination procedures (2), and 3 unspecified methods. The definitions of the populations considered to be stateless varied widely between countries and sources. The 2019 paper discusses a broad range of quality considerations for each of the existing data sources, including,

a) Difficulty in disentangling methodological changes from real changes in the numbers of stateless people from year to year. b) Reliance on administrative data from national authorities, where the methodology varies dramatically from country to country. Different concepts and definitions of statelessness are widely used depending on national laws and whether data arises from population registers, from records derived from statelessness determination procedures or in other records of displaced people such as refugees or IDPs.

c) Administrative data sources tend to be provided by OECD countries that are destination countries for asylum seekers, tending to overstate the displaced in reported data.

d) Countries using specialist household surveys designed to identify stateless people or those at risk of statelessness tend to be countries where there is a policy environment supportive of resolving statelessness. Other countries with unsupportive environments tend not to collect or report data on statelessness.

e) Census data is collected at ten-yearly intervals and statelessness results may be adjusted downwards for naturalisation cases, but not for upwards for demographic changes.

The first time UNHCR reported country data on statelessness was in its 2004 Global Trends report. Using data from 41 countries (of which just 30 were deemed reliable), it reported just under 1.5 million stateless persons, but it did not attempt to provide a global estimate of the phenomenon. Since then and for more than a decade has UNHCR used the figure of ("at least") 10 million people as its best estimate of the stateless population worldwide. In its most recent 2020 Global Trends report, the figure of " 10 million" global stateless people has been replaced with the more general term "millions". A more accurate estimate could be much larger, as the World Bank estimated more than 1 billion people without proof of identity [11]. There is no good estimate of the numbers of stateless people in the world, all that is known is that the number is in millions and may be tens of millions.

UNHCR's current estimate is based on yearly updated estimates from country reports, and on broad information from countries deemed to have large stateless populations. The total estimate is drawn from the 94 countries about which UNHCR has some data about statelessness, and this amounts to just 4.2 million stateless people. UNHCR country offices obtain yearly figures on the number of stateless people from a wide range of methods and sources, and the data is uploaded to UNHCR's Population Statistics Reference database. 
In addition to the quality issues found concerning data from countries that UNHCR does have reports on, a greater concern is the many countries known to have substantial numbers of stateless people that do not report their statelessness situation to UNHCR at all and which UNHCR has no other basis upon which to arrive at estimates. As noted above, global estimates are based on data concerning just 94 countries, and most of the data received by UNHCR does not meet the usual standards required for official statistics. This gap in the world's statistics, data quality issues and the low numbers of countries reporting on these marginalised people is of serious concern.

In recognition of these data problems and the recent progress made in improving statistics on displaced people and taking account of UNHCR's \#IBelong Campaign to End Statelessness, a small group of experts met in 2019 on the margins of an international meeting to discuss the feasibility of initiating a process to improve the global quantity and quality of official statistics on statelessness. This initial meeting considered how feasible it was to collect stateless data, as besides the politically contentious nature of publishing national estimates on stateless populations, there are serious methodological challenges to collecting better statistics about them.

\section{The evolution of the International Recommendations on Statelessness Statistics (IROSS)}

Following the first meeting of experts to consider the data quality issues outlined in the previous section, a somewhat more formal group was convened in Bangkok at the beginning of December 2019, comprising statisticians and other experts on the topic drawn from national statistical offices and from regional and international bodies [12]. This group initiated the development of International Recommendations on Statelessness Statistics (IROSS). Thereafter the work on developing the IROSS made good progress, with outline chapters prepared in 2020 with inputs from this group. During the $51^{\text {st }}$ UN Statistical Commission, UNHCR shared information about the early stages of development of the IROSS and received support for the continuation of the work from several Member States.

The work on the IROSS was subsequently included under the umbrella of the Expert Group on Refugee and IDP Statistics (EGRIS) in November 2020. EGRIS was established in 2016 by the UN Statistical Commission
(UNSC) at its $47^{\text {th }}$ Session and is tasked with addressing the statistical challenges around reporting on displaced people, including a lack of consistent terminology and difficulties in comparing statistics on displacement internationally. While some, but not all, stateless people lack citizenship because of displacement, many are stateless as a result of historical migration, often forced, of their parents, grandparents or even earlier generations. Stateless people are 'persons of concern' under UNHCR's mandate as UNHCR has a mandate from the UN General Assembly to identify and protect stateless persons and prevent and reduce statelessness itself [13].

The IROSS is expected to follow a similar format to that used for the International Recommendations on Refugee Statistics (IRRS) and the International Recommendations on IDP Statistics (IRIS), each of which was also prepared under the auspices of EGRIS. The draft IROSS currently includes:

1. Legal: Discussion of the legal background to statelessness.

2. Statistical framework: Chapter on defining statelessness for the purpose of statistical measurement, including definitions, and recommended basic tabulations.

3. Data sources: Chapter discussing the recommended data sources with examples drawn from countries with existing practice such as those presented in this paper.

4. Analysis: Chapter proposing recommendations for the analysis of statelessness data, including the causes of statelessness.

5. Coordination: Chapter on improving data coordination on statelessness including a discussion of data protection, confidentiality and data sharing, quality assurance, partnership and dissemination.

\section{Proposed framework for statelessness statistics}

The first step in developing the IROSS was to agree on the scope of the population to be included in the recommendations and to set out a statistical framework for classifying stateless people and related categories. This framework uses concepts and definitions based on the legal definition of statelessness and those definitions and concepts currently used by UNHCR and amended by the EGRIS for practical statistical application.

The proposed framework includes three main categories. These categories are set out in Box 1 and Fig. 1. 


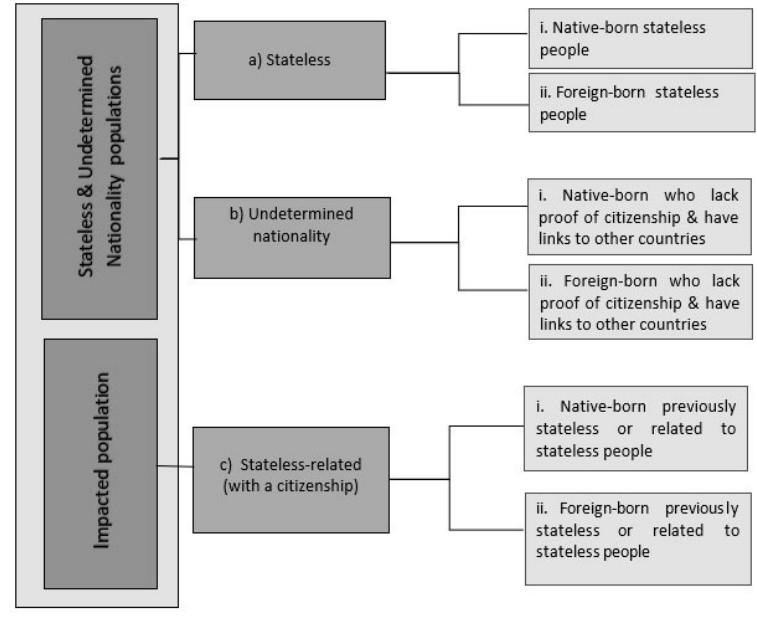

Fig. 1. Proposed definitional framework for International Recommendations on Statelessness Statistics.

Box 1. Proposed statelessness categories

Population in Scope of Statelessness Statistics

a) 'Stateless persons' include people who are currently without the citizenship of any country. They are classified as stateless either through self-declaration, or through recognition by competent government authorities, on an individual or group basis (e.g., the Rohingyas).

b) 'Persons of Undetermined Nationality' are people who lack proof of citizenship but who may possess an entitlement to nationality, and if so, could be assisted to obtain proof of citizenship by the relevant authorities. Those in the Undetermined Nationality category must lack proof of citizenship and have links to more than one country, that are real or perceived to be real by authorities, because of their place of birth, marriage, habitual residence, or descent from earlier generations who have migrated.

Categories a) and b) are the core population categories for the IROSS.

c) Stateless related people are those people impacted by statelessness, either as formerly stateless people, children of at least one stateless parent, or people living in a household with a stateless household member or members.

As discussed above, the concept of statelessness is based on the absence of nationality or citizenship. This is one of the main areas where new International Recommendations on Statelessness Statistics (IROSS) can lend clarity and help contribute to consistent approaches between international partners. To be in scope of the first two categories of the IROSS, as envisioned currently, a person has to lack any documentary or other proof of citizenship, and be either acknowledged as 'stateless' or be of 'undetermined nationality' because of their links to at least one other State. These links are either real or perceived to be real by the authorities because of their membership of a particular group (ethnic, religious or cultural etc.), or because of their migratory background, or due to State border changes.

A third category 'stateless-related persons' is also included in the scope of the IROSS. This additional category is included because the impact of statelessness on individuals and their families can be long lasting and therefore countries may wish to identify such persons and monitor and support their progress.

The framework for the IROSS also distinguishes between people who are native-born and those who are not. This subdivision is made because the recommended legal routes to obtaining nationality, or for the confirmation of nationality, differ according to a person's place of birth and migratory history. People who are nativeborn stateless individuals usually follow a different procedure to those who are foreign-born, who are by definition migrants to a country. Native-born people may also be impacted by migratory causes, if their parents or grandparents migrated, but this does not change the classification. This subdivision by country of birth also aligns with the proposed framework for International Migration [14].

The exact distinction between stateless and those with undetermined nationality [15] can only be finalised by a formal process which looks at the evidence on a case-by-case basis, for groups or individuals. For statistical purposes, unless the data are derived administratively from a legal or administrative process, then the allocation of individuals to the statistical category will be based on a respondent's answer to a question or estimated from a number of questions; and will be the best approximation possible based on the information collected. However as many people in scope of these recommendations have yet to have their statelessness or citizenship confirmed, many will fall into the category of undetermined nationality pending official confirmation. Thus, the category of undetermined nationality may in fact include some stateless populations, but it will also include many more who are not stateless.

\section{The major challenges found in collecting data from stateless people}

The definitional framework for statistics described in the last section clarifies the scope of statelessness statistics and the major classifications of those included and is a first step in improving data quality. However, populating this framework with statistics about the stateless population presents some significant challenges. This chapter includes a synopsis of many of the chal- 
lenges uncovered by the work so far. The next chapter includes a detailed discussion on the four main types of sources that can be used to provide statelessness data, together with some concrete case studies taken from the EGRIS subgroup working on IROSS to date. These successes in collecting data have led to very positive outcomes for formerly stateless people, but there are also considerable methodological challenges.

Collecting data about stateless people, or those at risk of statelessness, presents several challenges to the statistical community for the following reasons:

a. Firstly, those who are aware of their own statelessness will also know of their own potential vulnerability and may be reluctant to identify themselves in data collections, or reluctant to register vital events leading to undercounts in data collections.

b. Secondly, many may be unaware of their citizenship status problems if they have been living among populations where there are low rates of birth registration and where few possess formal identity documents, including proof of citizenship. Unaware that they are stateless, they will not self-identify themselves as stateless in surveys and censuses, although they may have found difficulties in registering vital events for themselves or their families.

c. Thirdly, attempts to identify the stateless in regular data collections may impact response rates among the broader category of undocumented people and minority groups. The recent issue surrounding the collection of citizenship in the decennial population census in the United States of America is an interesting case, as in the end citizenship was not included in the census due to the anticipated adverse impact on response rates [16].

d. Fourthly, attempts to identify the stateless population in administrative data are likely to fail without changes to the corresponding legal frameworks in respect of non-citizens' treatment in Civil Registration and Vital Statistics (CRVS) or Population Registers. National laws and bureaucratic obstacles often prevent those without proof of nationality, or with foreign documentation from appearing on population registers; they may also be prevented from registering their children's births and other vital events (see Manby [17]) despite the nearly universally ratified Convention on the Rights of the Child, requiring countries to register all births. However, stateless people can be identified in some administrative data including registers of foreign citizens, and records arising from asylum claims and immigration records [18]. As a result, stateless statistics globally tend to be biased towards stateless people in a migratory situation, or stateless migrants, as the countries reporting statelessness tend to be those with good administrative systems that are also destination countries for refugees.

e. Fifthly, attempts to include the stateless in the roll-out of CRVS may present risks to stateless people unless they are protected from immigration enforcement, as civil registration data is not usually protected under statistics legislation until data are passed to the statistical authorities. Protecting those identified will usually require protection regimes (e.g., laws that provide the protections afforded to stateless persons under the 1954 Convention on the Status of Stateless Persons) and legal pathways to citizenship to be put in place, where they do not exist already.

f. Sixthly, collecting statistics on stateless may lead to unacceptably large estimates of those potentially at risk of statelessness. For example, there have been pilot studies (e.g., in Cote d'Ivoire [19]), where the estimate of those who are at risk of stateless was large, even though many at risk of statelessness are outside of the proposed scope of statelessness statistics as currently envisioned.

\section{The policy context for resolving statelessness}

Notwithstanding the risks above, there is broad recognition that finding ways to collect better data has significant upside potential for stateless people and for the prevention and reduction of statelessness.

In 2009, UNHCR and its implementing partners conducted pilot surveys to identify the prevalence and causes of statelessness in Kyrgyzstan. Findings of the surveys resulted in the creation of an inter-ministerial process to address statelessness, and the adoption of a National Action Plan to Prevent and Reduce Statelessness. In July 2019, Kyrgyzstan became the first country to end all known cases of statelessness on its territory by identifying and confirming the nationality of nearly 14,000 stateless people.

In 2018, UNHCR partnered with UNICEF on a joint strategy on every child's right to a nationality in Albania focusing on legal reform and the improvement of the civil registration process, reducing the remaining barriers to obtaining a legal identity and observing the 
respect of basic human rights. Albania passed a new Law on Child Protection in January 2017, bringing new opportunities to enhance access to civil registration for children at risk of statelessness.

A 2019 study identified 1.6 million people as stateless or at risk of statelessness in Côte d'Ivoire, which hosts one of the world's largest stateless populations. In recent years, the Government of Côte d'Ivoire has stepped up action to end statelessness consistent with its accession in 2013 to the two Statelessness Conventions and the adoption of the Abidjan Declaration on the Eradication of Statelessness by the Economic Community of West African States (ECOWAS) in 2015. In 2017, ECOWAS Member States made West Africa the world's first region to adopt a binding Plan of Action to end statelessness [20]. Cote d'Ivoire has also adopted a National Plan of Action against statelessness and enacted important legal and institutional reforms to prevent individuals from becoming stateless. The African Union has also developed a Draft Protocol to the African Charter on Human and Peoples' Rights on the Specific Aspects of the Right to a Nationality and the Eradication of Statelessness in Africa [21].

Other regions of the world have also undertaken initiatives such as the UNESCAP Ministerial Declaration to "Get everyone in the picture" in Asia and the Pacific [22] which recognises the need to address disparities in the civil registration coverage of hard-to-reach and marginalized populations, including stateless people, and people without documentation. ESCAP's Bali Process Civil Registration Assessment Toolkit [23] is designed to assess the civil registration of refugees, asylum-seekers, stateless persons and persons of undetermined nationality.

\section{Data sources - some successes and concerns}

This section discusses the main sources of official statistics on statelessness, and discusses some of the successes in improving data, as well as some of the impediments to including statelessness in the usual data sources, e.g., administrative data, household surveys, population and housing censuses and modelled data, including data linking techniques.

\subsection{Administrative data}

In theory, population registers and administrative data should be able to identify stateless people and those with undetermined nationality if the data contains accu- rate information about citizenship, birthplace, ethnicity, and parentage. Administrative data potentially enables statisticians to identify the population of interest without the problems of respondent self-identification or accuracy, as the data will have been collected as a result of a legal or administrative process which verifies the data collected.

\subsubsection{Population registers}

Increasingly, population registers are becoming a primary source of official population statistics. In some countries they are used to replace traditional, questionnaire-based censuses, either by themselves, or in combination with other data sources. Population registers have been effectively used as a statistical data source for decades and they may be considered the logical product of the evolution of a vital statistics system [24]. Good population registers are available in several countries, especially in Northern Europe, where they have become an important source of information for various statistical surveys, including the population census.

The UN Principles and Recommendations for Vital Statistics Systems, Revision 3 advise that a population register should refer to the entire 'usually resident population' in the territory of a country. The definition of usual resident population is crucial to the identification of stateless persons, who may not be considered as part of the usually resident population. Their inclusion in a population register generally depends on their residency status. If this is irregular, then they may not appear on the register, excluding the stateless from official statistics estimates.

Few countries in the world have complete population registers, but those that do may be able to identify their stateless population, although those people whose status is entirely irregular and unknown to the authorities may not appear. The example below shows the use of the Norwegian Population Register as a source of stateless data.

\subsubsection{CRVS, legal identity agenda and statelessness}

A reliable population register depends on having good civil registration coverage and full coordination between the register and civil registration processes. Few countries have relatively complete civil registration. According to the United Nations Statistics Division (UNSD) only $73 \%$ of the countries, territories and areas register at least $90 \%$ of births that occurred. Furthermore, for death registration, only $68 \%$ of the countries, territories and areas have at least $90 \%$ cover- 
Example 1. Identifying Stateless People in the Norwegian Population Register.

In the Norwegian Population Register there is a code for citizenship for every resident of Norway, including a code for statelessness. There is also a code for unknown citizenship, which is used for very few individuals.

Information about the background of stateless people may be obtained from the variables "country (or place) of birth" and "country of previous residence" (for immigrants). These variables are drawn from a number of data sources and do not necessarily correspond to nationality, but they can indicate historical connections to other countries. In addition, for stateless children, data are usually linked to the parents' records via their ID number, which contain data on the parents' citizenship, country of birth and where they emigrated from.

Of Norway's total resident population of 5.4 million on 1 January 2021 there were 4.8 million Norwegian citizens, 0.6 million citizens of other countries, 1,708 stateless persons and 42 with unknown nationality ${ }^{1}$. Stateless people in Norway can apply for Norwegian citizenship after 3 years and most of them do so. Half of the stateless people identified become citizens after $31 / 2$ years. 95 per cent of the stateless people had received citizenship after $71 / 2$ years $^{2}$.

For non-Nordic immigrants to Norway their identity, including their citizenship, is checked and registered by the police and/or the Directorate of Immigration following a thorough procedure that utilizes all available information about the immigrant, including passport, birth certificate and other documents, as well as interviews. For citizens of the European Economic Area the checking is less comprehensive, and it is usually sufficient to show the passport or ID card. The process is particularly thorough (and lengthy) for asylum seekers, including stateless asylum seekers since citizenship is an important factor for the granting of asylum in Norway. Asylum seekers are assigned a temporary number (called D-number) when they apply for asylum and a regular person number (F-number) only when their application has been approved and they are given permission to live in Norway for six or more months.

\section{NOTES}

${ }^{1}$ Statbank, Statistics Norway. Retrieved from https://w ww.ssb.no/en/statbank/table/05196/tableViewLayout1/

${ }^{2}$ Kåre Vassenden, Kåre: Fra utenlandsk til norsk statsborgerskap gjennom mer enn forti år. [From foreign to Norwegian citizenship through more than forty years.) Reports 2020/31, Statistics Norway. Retrieved from https://www.ssb.no/en/befolkning/artikler-og-publikasjoner/fromforeign-to-norwegian-citizenship-through-more-than-forty-years

Kåre Vassenden of Statistics Norway, Trude Åsrum of the Tax Authority, and Helge Brunborg provided important input to this text

age [25]. Coverage of vital events is much poorer in the developing world. On the African continent just over $20 \%$ countries are thought to have complete coverage of birth registration, and in South America it is under $40 \%$ of countries (see Fig. 2). To help address this, the UN has recently launched a Legal Identity initiative [26], known as the UN Legal Identity Agenda, to help provide a legal identity for populations and to improve coverage of the registration of vital events.

The global rollout of the UN Legal Identity Agenda in support of the SDG target 16.9 to provide legal identity for all including birth registration by 2030 , may be helpful in preventing future statelessness by ensuring much higher levels of birth registration. Registration helps people to prove their names, place, and date of birth, but as Manby points out, it is not yet clear if the drive for 'legal identity' is a threat or an opportunity for the stateless. She goes on to discuss the double nature of identification and registration systems,

“. . . both as tools to build state capacity and social welfare systems, and to enable those registered to assert their rights as the SDG target intends, but also as instruments of exclusion, surveillance and control. Moreover, the process of sorting individuals into different nationalities is, by its nature, discriminatory and not necessarily empowering" [27].

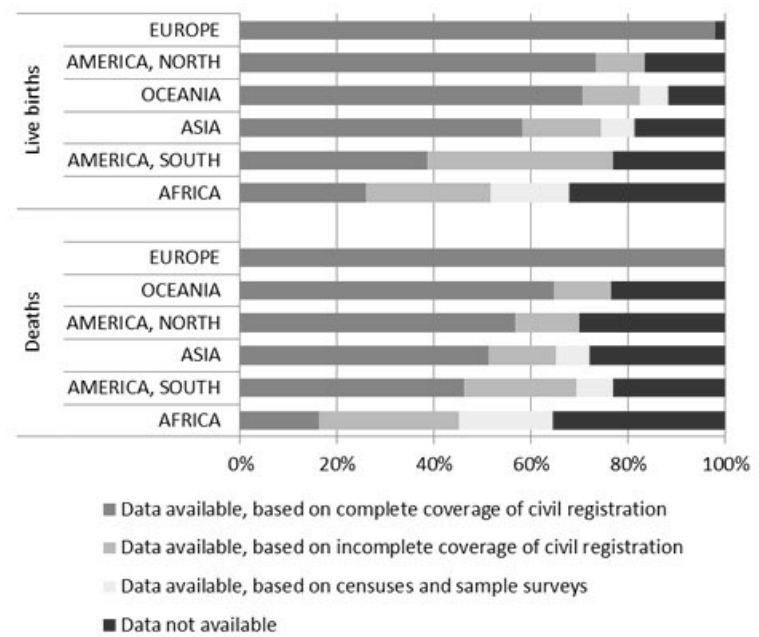

Fig. 2. Civil registration coverage worldwide.

As the global identity agenda rolls out, the number of children unable to prove their identity in the future is expected to fall as their births are registered and their identities confirmed. However, this will not resolve historical statelessness, and the smaller pool of those who remain without proof of identity or citizenship risks becoming increasingly marginalised and left behind un- 
Example 2. Thailand's measures to promote birth registration and reduce vulnerability to statelessness.

- The Registration of Residential Inhabitant Act B.E. 2534 (1991) and its Amendment B.E. 2551 (2008), which provide birth registration and a birth certificate to all children born in Thailand.

- On 7 December 2016, the Cabinet approved 2 resolutions to further address the issue of statelessness and promote the rights of stateless persons in Thailand.

1. The first resolution specifies the status and conditions to stay in Thailand for persons who are born in Thailand but do not possess Thai nationality. It grants foreign children born in Thailand the right to legally stay in Thailand, following the rights of their parents, and preventing them from being criminalised as illegal immigrants. This policy can potentially grant access to Thai nationality for up to 80,000 children, especially those living in the highlands and hinterlands in Thailand.

2. The second resolution enables foreign children born in Thailand to apply for Thai nationality, given the conditions of either their parents are from ethnic minority groups who were registered with the Ministry of Interior and have lived in Thailand for not less than 15 years, or their parents are from other groups but the children themselves have received a bachelor's degree or equivalent in Thailand. Children who are currently studying can also apply for Thai nationality to the Minister of Interior. Abandoned children can also apply if they have lived in Thailand not less than 10 years, certified by relevant agencies under the Ministry of Social Development and Human Security.

Source: Statement issued by Permanent Representative of Thailand to the UN, 10 October 2017. https:/www.ohchr.org/Documents/ Issues/Children/BirthRegistrationMarginalized/Thailand.pdf

less measures are taken to prevent this, as the majority will have proof of their identity.

As noted above, international norms require States to issue documentary proof of birth to children regardless of their own or their family members' documentation or residence status [28]. The UN Committee on the Rights of the Child and the Committee on the Protection of Migrant Workers have urged States to ensure that all children not only have their births registered immediately, but are also issued with birth certificates, irrespective of their or their parents' migration status (The Index of Statelessness, Thematic Briefing, 2020) [29]. However only half of the 24 countries featured in the European Statelessness Index demonstrate good practice in this regard, as not all children receive a birth certificate or proof of their birth, usually due to the parents' residence or documentation status.

Not only may the required documentation not be provided (see also Thailand study where despite a change in the law to provide birth certificates to all babies born in hospital almost half of a stateless group did not get them [30]), but registering a vital event may be risky for the family, whose lack of citizenship will be drawn to the attention of the authorities. International norms and good practice urge States to prohibit data sharing between health or registration officials and immigration enforcement authorities [31] to encourage universal birth registration, but this is often not the case. In Europe the ENS Statelessness Index [32] reports that most countries covered by the Index do not have mandatory reporting requirements for public officials to report people with irregular residence status to immigration authorities, but that few explicitly prohibit this in law or guidance. Three countries covered by the Index do place a requirement on the registration authorities to report irregular cases to immigration enforcement. Some advise that there should be an explicit firewall between immigration authorities and registration authorities to ensure confidentiality and to prevent immigration enforcement actions, while other experts take the view that States have the right to be informed about those present on their territory.

In practice, several countries have amended their civil registration laws (see Thailand Example 2 Box below) to ensure the civil registration of stateless groups, and this is often accompanied by support to help them to obtain nationality as a means of encouraging stateless people to come forward.

While the roll-out of improved CRVS and birth registration may help to prevent statelessness in the future, as noted above it will not resolve historical statelessness unless steps are taken to remove existing legal and administrative obstacles. Without changes in laws to protect those without proof of nationality, and to enable them to gain the necessary proof of citizenship or assistance, administrative data and CRVS systems may not be able to provide reliable official statistics without potentially compromising the security and wellbeing of those identified as lacking proof of identity.

\subsection{Household surveys}

Data collected under national statistics laws may offer much more data protection to the individuals identified, however the data is often more difficult to collect. Respondents must be knowledgeable and willing to report their status accurately. Collecting data about 
Example 3. Kenya Shona Survey.

During the first half of 2019, UNHCR Kenya in close cooperation and in collaboration with the Government of Kenya, through the Department of Immigration Services and the Kenya National Bureau of Statistics conducted a documentation and socio-economic study (SES) among the stateless Shona in Kenya.

The goal of the study was to provide the Government of Kenya and UNHCR with information on the Shona people living in Kenya. The Shona community migrated to Kenya from Zimbabwe and Zambia in the early part of the $20^{\text {th }}$ century had been living as stateless until they were granted citizenship in recent months.

The study collected information on their migration history, residence in Kenya, family circumstances and documentation held with the aim to prepare their registration as Kenyan citizens. Additionally, the socio-economic part of the study aimed to generate an overall picture of the socioeconomic conditions of the Shona community compared to Kenyan nationals. A listing of all Shona households using key informant lists and respondent-driven referral to identify further households was conducted by KNBS and UNHCR before the start of enumeration.

The study aim was to interview all households in Kenya with at least one Shona person living in them, and as a consequence of this full enumeration approach through a household survey no probabilistic sampling design was needed. Data collection resulted in the collection of documentation data on 2,084 individuals in 465 households. The questionnaire used in the Shona SES produces data comparable to national household surveys and other standard instruments. Modules on education, employment, household characteristics, and consumption and expenditure are aligned with the most recent national poverty survey, the 2015/16 KIHBS, and provides comparable results reported at the county and national levels.

those with irregular documentation may also adversely impact response rates, jeopardising the collecting of data in routine household surveys.

In many contexts stateless people will be a 'rare' population, that is they comprise a very small proportion of the total population of a country or region, but this is not always the case. In some countries with low levels of civil registration, those lacking proof of nationality, or the documents needed to obtain it, can make up a reasonably high proportion of the population. In these contexts, a household survey can be considered a viable option for stateless data.

Designing a sample is likely to require specialist sampling techniques in order to draw a sample of sufficient size for analytical purposes. In countries where desk research indicates low numbers of stateless people, or where they are highly clustered geographically, adding specialist statelessness modules to regular surveys such as Labour Force, MICS or Demographic and Health Surveys is unlikely to be successful. A specially designed survey is likely to be required.

Specialist surveys are expensive and can be difficult to justify in the work programmes of statistics bureaux, particularly as the respondents are by definition noncitizens. Nevertheless, there are a growing number of countries which recognise that they have a significant number of residents who do not hold proof of citizenship and find it difficult to obtain it for reasons of historical migration, cultural norms, administrative oversight, national border changes or State succession. In such countries, surveys can be helpful tools to gather more information about the populations concerned and their specific challenges, including their socio-economic sta- tus. Where there has been the political will to resolve these citizenship problems, national authorities have developed policies or made other adjustments to find pathways to citizenship (see Kenya Shona Survey and subsequent conferral of Kenyan nationality to the Shona people [33]).

There are also examples of successful surveys using standard two stage sampling techniques that have provided the authorities with useful information about the size and causes of those at risk of statelessness due to low levels of civil registration and high levels of historical migration (see Côte d'Ivoire study below [34]).

Regular household surveys may also offer opportunities to add variables which could be linked to other data sources or used with other data to provide better estimates of the stateless population by using modelling techniques (see 7.4 below).

\subsection{Population and housing censuses}

The population and housing census is a useful source of data for estimating statelessness. Questions which ask directly about citizenship and statelessness can be combined with other variables which might be used as statelessness proxies to correct for under-reporting. Under-reporting occurs because respondents may not be familiar with the statelessness concept or may not wish to identify themselves as stateless. Questions trialled in the recent 2019 Kenya Census found many people declaring themselves as stateless, after being reassured in a publicity campaign. Others without citizenship were found to be reluctant to declare themselves 
Example 4. Cote d'Ivoire Statelessness Survey.

\section{Context and background}

Following the Abidjan Declaration, an Action Plan for the eradication of statelessness over the period 2017-2024 known as the "Banjul Action Plan" was adopted in Monrovia in June 2017. The CAPRA study is in accordance with to action 10 of the Global Action Plan "Improve quantitative and qualitative data on stateless populations".

The National Institute of Statistics (INS) of Côte d'Ivoire in collaboration with several Government Ministries and with support from UNHCR, UNFPA and UNICEF conducted a Mapping of People at Risk of Statelessness (CAPRA) study, with the aim of determining and mapping the number of people at risk of statelessness in its territory. The study was intended to estimate the number of people who were at risk of statelessness, this 'at risk of statelessness'sets a much lower standard for inclusion in the scope of statelessness statistics than does the proposed IROSS framework.

In the study a "Person at risk of statelessness" is defined as a person who is unable to meet the necessary documents or conditions to be certified or assigned a nationality. The proposed IROSS definition includes a link, real or perceived to another country and sets a much higher threshold. This lower standard is a very helpful concept in a country where a high proportion of the resident population are without identity documents. The study was regarded as 'experimental statistics'or a trial survey for potential collections of official statistics, and has been used by officials in considering policy options for resolving the risk of statelessness in the resident population.

- Those at risk of statelessness were assessed using a complex set of definitions involving country of birth, lack of registration of birth, lack of proof of nationality or documentation proving parentage - this is a lower threshold than that proposed to be in scope of the IROSS population, as a person would need to both lack proof and have a link to another country.

- Those at high risk of statelessness were either born abroad and had no documents to prove their nationality or parentage or were born in the Ivory Coast but had no proof of nationality or the nationality of deceased parents - this is a lower threshold than the undetermined nationality category proposed for the IROSS.

- Those people who have tried and failed to obtain proof of nationality were assessed to be at very high risk, this category corresponds to the IROSS stateless definition.

\section{Methodology}

A household survey was conducted in 2018 using a sample of 9,240 households living in 462 Enumeration Zones (ZD): together with a qualitative study of 81 contextual interviews, 150 individual interviews and 20 focus groups. A two-stage sample design was used to sample from the resident household population. At the first stage, the sampling frame used was the General Population and Housing Census of 2014. From this, the 462 EAs were drawn systematically, with a probability proportional to size (PPS) of each District. At the second stage the selected EAs, a systematic sample of 20 households was drawn from the all the households identified by household listing

\section{Results}

The preliminary results of the study provided an initial estimate of population living in Côte d'Ivoire who are at some risk of statelessness, but that most of these are at a low risk of statelessness with some three quarters of those assessed to be at risk of statelessness were thought likely to be eligible for Ivorian nationality. Only $15 \%$ of the population had not had their births registered, but only half the sample held birth certificates or their equivalent, with two thirds of those aged over 16 years holding proof of nationality.

Despite the relatively high incidence of the risk of statelessness, the results show that more than half of people (54.6\%) have not heard of the concept of statelessness.

as stateless and identified themselves as members of ethnic groups within their community.

The recommended census questions on country of citizenship, giving the options of "none" or "stateless" and the respondent's country of birth can support the estimation of the size of the stateless population and estimation can be enhanced by supplementing these questions with other questions found to be highly correlated with statelessness in the national context. However, asking directly about statelessness alone is likely to result in undercounts. Where citizenship issues are politically sensitive non-response rates may be increased. Lessons learnt from the 2010 census round for the purpose of estimating migration (UNFPA, March 2018) found only $66 \%$ of all censuses included both questions on country of birth and citizenship, this limits the use of censuses for statelessness estimation, and for classifying people by their birthplace as is being recommended both for statelessness statistics and in the Revised Overarching Conceptual Framework on International Migration [35] recommended by the Expert Group on Migration Statistics. It is hoped that these core questions will be more widely used in the 2020 round, even if their direct use for estimating statelessness is limited. 
Example 5. Kenyan Population and Housing Census 2019

The 2019 Kenyan and Population and Housing Census was successfully conducted in August 2019. For the first time the same detailed questionnaire was used for the whole population including refugees, asylum seekers and stateless populations. Previously a shorter version of the questionnaire was designed for these populations. There were no additional questions on UNHCR's populations of concern, but additional response categories of existing questions were included to accommodate stateless populations.

The question on nationality included codes for stateless/no nationality/none and codes for the various Kenyan ethnicities. It was possible to select known stateless groups in the tablet used to collect data after selecting stateless or no nationality.

Question P16: What is < NAME >'s ethnicity or nationality?

- For Kenyans, write ethnicity code.

- For non- Kenyans, write code for nationality.

The question on reason for migration (both internal and international) captured IDPs, refugees and asylum seekers in respect of their last move.

Question P23 Why did $<$ NAME $>$ move to the current place of residence?

- 1 = Work/Employment.

$-2=$ Business.

$-3=$ Marriage.

$-4=$ Education

$-5=$ Settlement.

$-6=$ Relocation due to development.

$-7=$ Conflict/Disaster displacement.

$-8=$ Refugee.

- $9=$ Asylum Seeker.

- 10 = Family Related Movement.

$-11=$ Retirement.

$-12=$ Visiting.

$-99=\mathrm{DK}$

UNHCR contributed to the preparation of the census manuals especially with respect to the additional information on refugees/asylum seekers and stateless populations as well as training of field staff and monitoring of the census.

UNHCR and KNBS developed information materials for the refugees and stateless populations and together with partners reached out to the stateless communities to help them understand the census, questions, and protection of the data. The communities were also assured that there would be no changes in their legal status and no intimidation by the authorities as a result of the responses provided.

The results of the census however indicated that the public education and campaign did not completely convince the stateless populations to self-identify themselves, as the numbers were lower than expected. In addition, the drop-down menu on the tablet used for data entry did not list all the known stateless communities. Post-census evaluation also indicated that most stateless population felt safer to self-identify with other known Kenyan tribes or did not provide any information on nationality.

Published results from the census (Kenya Population and Housing Census 2019 Volume IV - Distribution of population by age and sex, December 2019) show a total figure of 6272 individuals self-identified as stateless. Another 33,358 did not provide any information on nationality. Results are found Table 2.3 .1 on pages 423 and 424 in the census report 4.

As part of the UN Legal Identity Agenda countries are urged to also collect data about the possession of identity documents among their entire resident population, particularly birth certificates, to monitor the civil registration and vital statistics coverage in their country. As noted above, Target 16.9 of the Sustainable Development Goals urges Member States to "provide legal identity for all, including birth registration", and this is to be monitored using Indicator 19.9.1: Proportion of children under 5 years of age whose births have been registered with a civil authority, by age. This will be useful in estimating statelessness as the lack of identification documents may indicate a risk of statelessness in populations, when used in conjunction with other variables.
Censuses are particularly useful for modelling and data linkage techniques where additional characteristics are collected that are relevant to the characteristics of stateless people in the national context. These characteristics include birth registration; religion, ethnicity or language spoken, where statelessness is related to ethnic groups (e.g., Kenya 2019); or country of birth of parents. The responses are of course self-reported or provided by a household representative, but the data may usefully provide potential information to help design subsequent surveys or for modelling exercises to estimate the size of the stateless population.

\subsection{Modelling and data linkages}

Statistical and demographic models can help to esti- 
mate population size in the presence of low-quality and missing data. Possible techniques to statistically model stateless population sizes include: population projections with cohort component and related methods, adjusting census counts of stateless persons for known underreporting, and the identification of at-risk groups of migrants in a country under consideration of the legal framework for citizenship. Such approaches need to incorporate the uncertainty of data and models and will result in possible ranges rather than single point estimates. The Inter-Agency Group on Statelessness Estimation (IGSE) is an expert-driven effort supported by a technical advisory group to develop a methodological framework to estimate stateless population sizes using statistical and demographic techniques.

Statistical models should be seen as complementary, not as substituting for the important work of collecting better data on stateless persons. They will nonetheless be required for reliable regional and global estimates of stateless population sizes for the foreseeable future. Firstly, current efforts for better and more data collection at the national level will only result in gradual and slow improvements. Secondly, it is likely that for reasons related to capacity, resources and political will, a substantial number of countries will not start reporting data on stateless populations in the short to medium term for the foreseeable future. Improved primary data even from a limited number of countries will, however, certainly improve the reliability of estimates of population sizes from models.

\section{The road ahead}

A Technical Progress Report on the work undertaken by EGRIS on statelessness statistics is currently being developed. The Report is expected to be submitted to the Fifty-third meeting of the UN Statistical Commission (UNSC) in 2022 and will take the form of a discussion paper that includes the proposed statistical framework, the progress made in collecting data, and some early recommendations to overcome some of the challenges discussed in this paper. Before its submission, the Technical Progress Report will be peer reviewed by statelessness experts and representatives from national, regional, and international organizations with relevant expertise in the area of statelessness statistics. This process will ensure that their views and feedback are incorporated into the Technical Progress Report and further development of the IROSS. The development of the IROSS is thus a work in progress and will continue to evolve; this article reflects the work of the EGRIS Subgroup on Statelessness at the time of writing.

For the remainder of 2021, efforts to refine the concrete recommendations in the IROSS will continue. In parallel, work is ongoing that will support better quality statelessness estimates, using modelling and data linkages. In March 2022, when the Technical Progress Report will be presented to the UNSC, it is hoped that a side event will take place at its margins providing an additional opportunity for Member States and other interested parties to comment on of the proposed framework for the IROSS to date.

In 2022, further involvement and inputs by national statistical bureaux will be needed to support the continuous development of the recommendations, including more concrete examples of good practice. Global consultations on the IROSS among members of the UNSC and the wider global community will be organized between September and October 2022. The feedback from this process will support EGRIS to finalise the IROSS ahead of its official submission to the UNSC for formal endorsement.

Of course, adoption of the IROSS will be only the first step in a long journey to promote implementation of the recommendations, but it will be an important and overdue one when it comes to the state of the international community's knowledge on the important problem of statelessness.

The third phase of EGRIS' mandate supports the implementation of the international recommendations on refugee, IDP and statelessness statistics. Capacity building activities have already started for refugee and IDP statistics, with EGRIS providing technical support to countries to implement their recommendations. These capacity building activities support best practice and knowledge dissemination, peer-to-peer learning and exchange as well as refinement of areas of the recommendations that require further work and development. These approaches are expected to be extended to the implementation of the IROSS, to measure progress and to develop durable solutions to ending statelessness.

The IROSS when adopted will help to contribute to the production of better quality, harmonized and comparable statistics. However, there also needs to be a significant increase in the number of countries producing statistics on their stateless populations. The IROSS will provide methodological recommendations which will enable countries to include the collection of data in their statistical work programmes. At the same time, the improvement in birth registration and vital statistics is needed to help prevent future statelessness and 
facilitate better data on those already at risk of statelessness. Improvements in CRVS will require civil registration laws and administrative systems to be modernised to enable stateless people to register vital events safely, and to find remedies to their citizenship difficulties. The examples from Kenya and Cote d'Ivoire show that studies and data collection can identify some of the people at risk, and lead to some long-resident stateless populations gaining citizenship. Better data can also motivate countries to undertake the reforms to nationality laws needed to prevent statelessness from occurring in the first place, as evidenced by reforms in a number of European countries following the public release of statelessness studies by UNHCR [36]. We can hope that additional countries will follow suit as data improves, both before and following the end of UNHCR's \#IBelong Campaign in 2024.

\section{Acknowledgments}

The authors would like to thank Kåre Vassenden of Statistics Norway, Trude Åsrum of the Tax Authority, and Helge Brunborg, who provided important input to this text. The national authorities of the country examples cited are also thanked for their important contributions towards developing successful methodologies for collecting data on stateless populations. Finally, thanks are due to the EGRIS Secretariat for its help and support in the development of this article.

\section{References}

[1] See, e.g., I am Here, I Belong - IBELONG (unhcr.org) and Stateless minorities and their search for citizenship - IBELONG (unhcr.org).

[2] See High-Level Segment On Statelessness I Resources - IBELONG (unhcr.org) for more information.

[3] See The Sustainable Development Agenda - United Nations Sustainable Development and "The Sustainable Development Goals and Addressing Statelessness" at 58b6e3364.pdf (refworld.org).

[4] The 1961 Convention on the Reduction of Statelessness contains the key international standards that prevent statelessness from occurring in the first place. There are complementary standards in a number of international human rights treaties, including the Convention on the Elimination of all forms of Discrimination Against Women.

[5] 25 countries globally do not allow mothers equal rights to confer citizenship on their children as compared with fathers; for more information about this see Refworld I Background Note on Gender Equality, Nationality Laws and Statelessness 2021.

[6] See Refworld I UNHCR and UNICEF: Background Note on Sex Discrimination in Birth Registration.
[7] See UNHCR - Global Action Plan to End Statelessness: 20142024, Action 10.

[8] In fact, most stateless people are not displaced and reside where they were born and have lived their whole lives, and only some of the world's refugees and migrants are stateless. The most prominent example is the Rohingya in Bangladesh, who are both stateless and refugees.

[9] See https://ec.europa.eu/eurostat/web/products-manuals-and -guidelines/-/KS-GQ-18-004 and https://unstats.un.org/unsd/ demographic-social/Standards-and-Methods/files/Principles_ and_Recommendations/International-Migration/2018_1746_ EN_08-E.pdf.

[10] See, Lily Chen, Petra Nahmias, Sebastian Steinmueller. 'UNHCR Statistical Reporting on Statelessness'; UNHCR Statistics Technical Series: 2019/1 https://www.unhcr.org/statistics/unhcrstats/5d9e182e7/unhcr-statistical-reporting-statelessness.html.

[11] See http://id4d.worldbank.org/global-dataset.

[12] Participants at the Bangkok meeting included experts from national statistical offices, and line ministries, with 16 countries represented from across Europe, Asia and Africa. Staff from UNHCR, UNFPA and UN regional commissions (UNESCAP, UNECA and UNESCWA) also attended to support the discussions at the meeting

[13] See, e.g., UN General Assembly Resolution 61/137 of 2006.

[14] UNSC 52nd Session Item 3(g) https://unstats.un.org/unsd/ statcom/52nd-session/documents/2021-11-MigrationStatsE.pdf.

[15] This proposed distinction is made for statistical rather than legal purposes, international law defines statelessness as the absence of any citizenship, but as many people have yet to have their statelessness or citizenship tested, many will be in an undetermined category pending a full investigation.

[16] Haberman, $\mathrm{H}$ and Louis, Thomas A. Can the fundamental principles of official statistics and the political process coexist? Statistical Journal of the IAOS. 2020; 36: 347-353.

[17] Manby, Bronwen. Legal Identity for All' and Statelessness: Opportunity and Threat at the Junction of Public and Private International Law. https://papers.ssrn.com/sol3/papers.cfm? abstract_id=3783310.

[18] Although it can be difficult to identify those who are stateless or of undetermined nationality from those who are undocumented having lost their documentation as a result of displacement.

[19] See https://www.refworld.org/docid/615463624.html and https://www.unhcr.org/blogs/mapping-statelessness-cotedivoire/

[20] See Banjul Plan of Action of the Economic Community of West African States on the Eradication of Statelessness 20172019 https://www.refworld.org/pdfid/5915c88a4.pdf.

[21] See draft protocol memorandum https://au.int/sites/default/ files/newsevents/workingdocuments/35139-wd-pa22527_ e_originalexplanatory_memorandum.pdf and https://au.int/en/ newsevents/20180507/member-states-experts-meeting-draftprotocol-african-charter-human-and-peoples, Abidjan May 2018 .

[22] See https://getinthepicture.org/sites/default/files/resources/ Ministerial.Declaration.English.final_0_0.pdf.

[23] See https://getinthepicture.org/resource/bali-process-civilregistration-assessment-toolkit.

[24] The term "population register" was defined in 1969, in the publication entitled Methodology and Evaluation of Population Registers and Similar Systems (United Nations, 1969), as “an individualized data system, that is, a mechanism of continuous 
recording, and/or of coordinated linkage, of selected information pertaining to each member of the resident population of a country in such a way to provide the possibility of determining up-to-date information concerning the size and characteristics of that population at selected time intervals" (chap. I.A).

[25] See https://unstats.un.org/unsd/demographic-social/crvs/.

[26] See https://unstats.un.org/legal-identity-agenda/.

[27] Manby ibid.

[28] See the Convention on the Rights of the Child, Article 7 and Joint General Comment No. 4 (2017) of the Committee on the Protection of the Rights of All Migrant Workers and Members of Their Families and No. 23 (2017) of the Committee on the Rights of the Child on State obligations regarding the human rights of children in the context of international migration in countries of origin, transit, destination and return: https://www.refworld.org/docid/5a12942a2b.html.

[29] https://index.statelessness.eu/sites/default/files/ENS-Birth_ registrations-StatelessnessINDEX_briefing.pdf, Thematic Briefing May 2020.

[30] Mahidol University and UNICEF Thailand, June 2021, Publication An Assessment of Access to Birth Registration among Migrant Children The quantitative study.
[31] Joint General Comment No. 4 (2017) of the Committee on the Protection of the Rights of All Migrant Workers and their Families \& No. 23 (2017) of the Committee on the Rights of the Child: https://www.refworld.org/docid/5a12942a2b.html.

[32] The Index contains comparative data for 27 European countries. They have been chosen based on the capacity of ENS Members to participate as country experts and a desire to reflect a mix of countries with dedicated statelessness determination procedures, mechanisms to prevent and reduce statelessness, countries without, and countries in different sub-regions of Europe, with different legal systems. See https://index. statelessness.eu/countries.

[33] See https://reliefweb.int/report/kenya/understanding-socioeconomic-conditions-stateless-shona-community-kenya.

[34] See https://www.refworld.org/docid/615463624.html and https://www.unhcr.org/blogs/mapping-statelessness-cotedivoire/

[35] See UNSC Fifty-second session, 1-3 and 5 March 2021, Item $3(\mathrm{~g})$ of the agenda.

[36] See https://www.refworld.org/statelessness.html. 